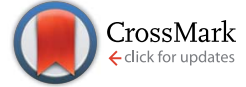

Cite this: RSC Adv., 2015, 5, 50234

\title{
Stable negative differential resistance in porphyrin based $\sigma-\pi-\sigma$ monolayers grafted on silicon $\dagger$
}

\author{
Kavita Garg, ${ }^{a}$ Chiranjib Majumder, ${ }^{\text {b }}$ Shiv Kumar Gupta, ${ }^{c}$ Dinesh Kumar Aswal, ${ }^{c}$ \\ Sandip Kumar Nayak ${ }^{a}$ and Subrata Chattopadhyay ${ }^{\star a}$
}

Two Si-based hybrid self-assembled monolayers were synthesized by electro-grafting two di-O-alkylated porphyrins as the $\sigma-\pi-\sigma$ systems. The monolayers showed a stable and reversible negative differential resistance (NDR) property at room temperature. The monolayer, fabricated using the porphyrin with fluorophenyl groups was more compact and showed a tenfold peak-to-valley ratio (PVR) relative to the other similar system devoid of the fluorine atoms in the porphyrin moiety. This suggested better preorganization of the former, possibly by hydrogen bonding through the electro-negative fluorine atoms.

Received 20th May 2015 Accepted 1st June 2015

DOI: $10.1039 / c 5 r a 09484 d$

www.rsc.org/advances doped Si (111) surfaces, ${ }^{8 a, b}$ diamond films, ${ }^{8 c}$ and thiols on $\mathrm{Au}$ surfaces (all at room temperature), ${ }^{8 d}$ (ii) $2^{\prime}$-amino-4, $4^{\prime}$-di(ethynylphenyl)-5'-nitro-1-benzenethiol, sandwiched between two metal electrodes (observed at $60 \mathrm{~K}$ ), ${ }^{2 b}$ (iii) $\mathrm{Pd} /$ ferrocene selfassembled layer/Au structure, ${ }^{8 e}$ (iv) cyclopentene molecules, deposited on p-type hydrogen free $\mathrm{Si}(001)$ (observed at $80 \mathrm{~K}){ }^{2 \boldsymbol{b}}$ (v) styrene and 2,2,6,6-tetramethyl-1-piperidinyloxy, deposited on degenerately doped $\mathrm{Si}$ (100) reconstructed surfaces, ${ }^{8 f}$ and (vi) disulfide molecules deposited on $\mathrm{Si}^{8 g}$ In an interesting study, organic molecules deposited on doped Si (100) surfaces by ultrahigh vacuum scanning tunnelling microscope (STM) showed room temperature NDR behaviour that was decided by the nature of the molecules and the dopants. ${ }^{8 h}$ In all these cases, the resonant and off-resonant electronic tunneling mechanism provide satisfactory explanations for the NDR behavior. ${ }^{9}$ A large peak-to-valley ratio (PVR) in the NDR effect, required for fast switching and functioning of the device at room temperature with high reproducibility are the prerequisites for applications in hybrid nanoelectronics. Most of the reported molecular hybrids, exhibiting the NDR behaviour did not fulfil many of these criteria, and the measurements were carried out under ultra-high vacuum in certain cases. Some of the devices were made using expensive techniques such as STM, and require appropriate biasing and doping. Due to the variation of the electronic structures of the STM tips during experimentation, NDR may occur at different bias magnitudes and polarities. Also, routine impurity doping is problematic due to uncertainty of its distribution. ${ }^{10}$

Thus, despite impressive progress in molecular electronics, search for alternate single molecules or a finite ensemble of selfassembled molecules showing NDR property at a lower bias is currently an active research area in molecular electronics. Amongst the electron-rich organic molecules, porphyrins ${ }^{\mathbf{1 1}}$ are used extensively in fabricating molecular devices because they (i) form stable $\pi$-cation radicals, and exhibit two accessible
${ }^{a}$ Bio-Organic Division, Bhabha Atomic Research Centre, Mumbai, 400085, India. E-mail: schatt@barc.gov.in

${ }^{b}$ Chemistry Division, Bhabha Atomic Research Centre, Mumbai, 400085, India ${ }^{c}$ Technical Physics Division, Bhabha Atomic Research Centre, Mumbai, 400085, India $\dagger$ Electronic supplementary information (ESI) available. See DOI: 10.1039/c5ra09484d 
cationic states in monomeric forms; ${ }^{\mathbf{1 2 a}-\boldsymbol{e}}$ (ii) have long charge retention times, hence less power consumption, (iii) are highly stable, ${ }^{12 f}$ and (iv) can form self-assembled structures. ${ }^{12 g}$ Despite all these attributes and theoretical proposition, ${ }^{8 \boldsymbol{h}, 13}$ scarce attention has been paid to construct porphyrin-based NDR devices experimentally. Previously, the $J-V$ curves of some porphyrin-metal ions combinations showed NDR-like effect. ${ }^{\mathbf{1 4 a - c}}$ We have also found electrical bistability and current rectification properties of some porphyrin monolayers on Si surfaces. $^{14 d, \boldsymbol{e}}$ More recently, metal-free and Zn-bis-porphyrin molecules have been used as efficient chemosensors for $\mathrm{Cl}_{2}$ and $\mathrm{NH}_{3}$ gases in air. ${ }^{15}$ Presently, we fabricated redox-active porphyrin monolayers on Si and investigated the possibility of using the oxidation states of the porphyrin molecules as molecular-scale information storage systems. The prime aim was to develop devices that are environmentally stable, and show high repeatability and easy processability. Studies on the $J-V$ characteristics of the hybrid systems revealed stable, reversible, reproducible, and room temperature NDR behaviour by both the systems. We also demonstrate that the NDR property can be tuned by subtle changes in the porphyrin structure by incorporating an electro-negative substituent (F) at the mesophenyl groups.

\section{Results and discussions}

Given the importance of the molecular bridges in nano-devices, design of the organic molecule is crucial in attaining our objectives. The molecular design was conceived keeping in mind that the energy gap $(\Delta E)$ between the energy states (LUMO/HOMO) of the molecular bridges and the Fermi levels of the donor and acceptor units control the electron-transfer rate and current flow. ${ }^{16}$ For large $\Delta E$, the ET process is dominated by a "through-bond" non-resonant tunnelling mechanism, where the organic molecules generally act as poor electron conductors. However, alteration of their electronic structures can induce the ET process via a resonant tunnelling or a hopping mechanism. The change from a non-resonant to resonant tunnelling would result in an abrupt increase in the current, and the measured $J-V$ curves would show NDR characteristics. ${ }^{17}$ Resonant tunnelling requires a double potential barrier along the electron transfer coordinates. Earlier, we have proposed a possible physical origin for such a double potential barrier, and hypothesized that the $\sigma-\pi-\sigma$ monolayers, grafted on Si might show NDR effect. ${ }^{\mathbf{1 4 d}}$ The $\sigma-\pi-\sigma$ molecular architecture is analogous to the tunnel diode, with a 'quantum well' surrounded by thin layer barriers. ${ }^{18}$ Here, the $\pi$-moiety (a conjugated molecule) acts as a quantum well and the $\sigma$-moieties (alkyl chains) as the tunnel barriers. The NDR effect in such a monolayer is expected, if electrons tunnel through some resonant states of the $\pi$-moiety. Our previous studies with $N$-(2-(4-diazoniophenyl) ethyl)- $N$-hexylnaphthalene-1,8,4,5 tetracarboxy diimide tetrafluoroborate as a $\sigma-\pi-\sigma$ molecule showed poor NDR effect (PVR $\sim 10$ ) with hysteresis, but established the hypothesis. ${ }^{19}$ Hence, we synthesized two new di-O-alkylatedporphyrins $\mathbf{5 a}$ and $\mathbf{5 b}$ with tetraphenylporphyrin (TPP) and a fluoro-TPP derivatives as the respective quantum wells ( $\pi$ moiety), and a $\mathrm{C}_{6}$-alkyl chain and $\mathrm{C}_{11}$-alkenyl chain as the barriers. The choice of the alkenyl chain as one of the barriers was a part of the molecular design, because this helped in electro-grafting monolayers of the molecules on Si (111) surfaces. Subsequently, the possibility of using the oxidation states of the porphyrin molecules as molecular-scale devices was investigated using the fabricated porphyrin-Si hybrids.

\section{Synthesis of porphyrins $5 a$ and $5 b$}

The classical one-pot method of Adler and Longo involving an acid-catalyzed reaction between pyrrole and an aryl aldehyde under refluxing conditions is suitable for the synthesis of symmetric ( $\mathrm{A}_{4}$-Por) or partially symmetric $\left(\mathrm{A}_{3} \mathrm{~B}\right.$-Por) porphyrins, where $\mathrm{A}$ and $\mathrm{B}$ are the meso-aryl substituents. ${ }^{20 \boldsymbol{a}}$ Extension of the method to synthesize porphyrins, bearing two or more types of meso-substituents provides a statistical mixture of six porphyrins from which isolation of pure compounds becomes extremely difficult. Hence, we adopted Lindsey's method involving a " $2+2$ " route using a dipyrromethane-1,9-dicarbinol and a dipyrromethane (bearing ABC- and D-substituents, respectively) for the synthesis of the target porphyrins 5a and $5 \mathbf{b} .^{20 b}$ This involved a base-catalyzed alkylation of 4-hydroxybenzaldehyde with 1-bromohexane and 11-bromoundec-1-ene to furnish the aldehydes $\mathbf{1 a}$ and $\mathbf{1 b}$ respectively. The aldehydes were individually subjected to a trifluoroacetic acid (TFA)-catalyzed condensation with pyrrole to yield the dipyrromethanes $\mathbf{2 a}$ and $\mathbf{2 b}$ respectively. Compound $\mathbf{2 a}$ was subsequently acylated with benzoyl chloride (3a) or 4-fluorobenzoyl chloride (3b) using EtMgBr as the base to afford the ketones $4 \mathbf{a}$ and $\mathbf{4 b}$ respectively. This reaction is tricky and produces both mono- and di-acylated products if the stoichiometry and reaction temperature are not maintained carefully. The ketones $\mathbf{4 a}$ and $\mathbf{4 b}$ were subsequently reduced with $\mathrm{NaBH}_{4}$ and the resultant unstable diols were converted to the porphyrins $\mathbf{5 a}$ and $\mathbf{5 b}$ via a TFA-catalyzed condensation with $\mathbf{2 b}$ followed by a 2,3dichloro-5,6-dicyano-1,4-benzoquinone (DDQ) oxidation, the three-steps process being carried out in one-pot (Scheme 1).

\section{Preparation of the grafted organic assembly}

Physisorption of organic molecules as Pockels-Langmuir (PL) films or by vapor-phase deposition on electrodes is often used to fabricate hybrid organic electronic devices. However, ordering of PL films is usually achievable with amphiphilic molecules only, restricting the molecular design. On the other hand, the vapor-phase deposition method often results in poor deposition yields, disordered packing and random orientations. Further, the physisorbed molecules often move to seek a lower energetic state on the surface, or in response to an applied electric field. Instead, covalent linking of organic molecules to metal/ semiconductor surfaces provides a better alternative. ${ }^{21}$ Extensive work has been carried out by attaching organic thiol molecules to Au electrodes. But, the Au surfaces are reported to be thermally unstable. ${ }^{22}$ Monolayers of alkyl silanes have been grafted on $\mathrm{SiO}_{2}$ surface, but the multi-steps protocol required stringent reactions conditions such as control of the optimized temperature and anhydrous conditions. In addition, many of 


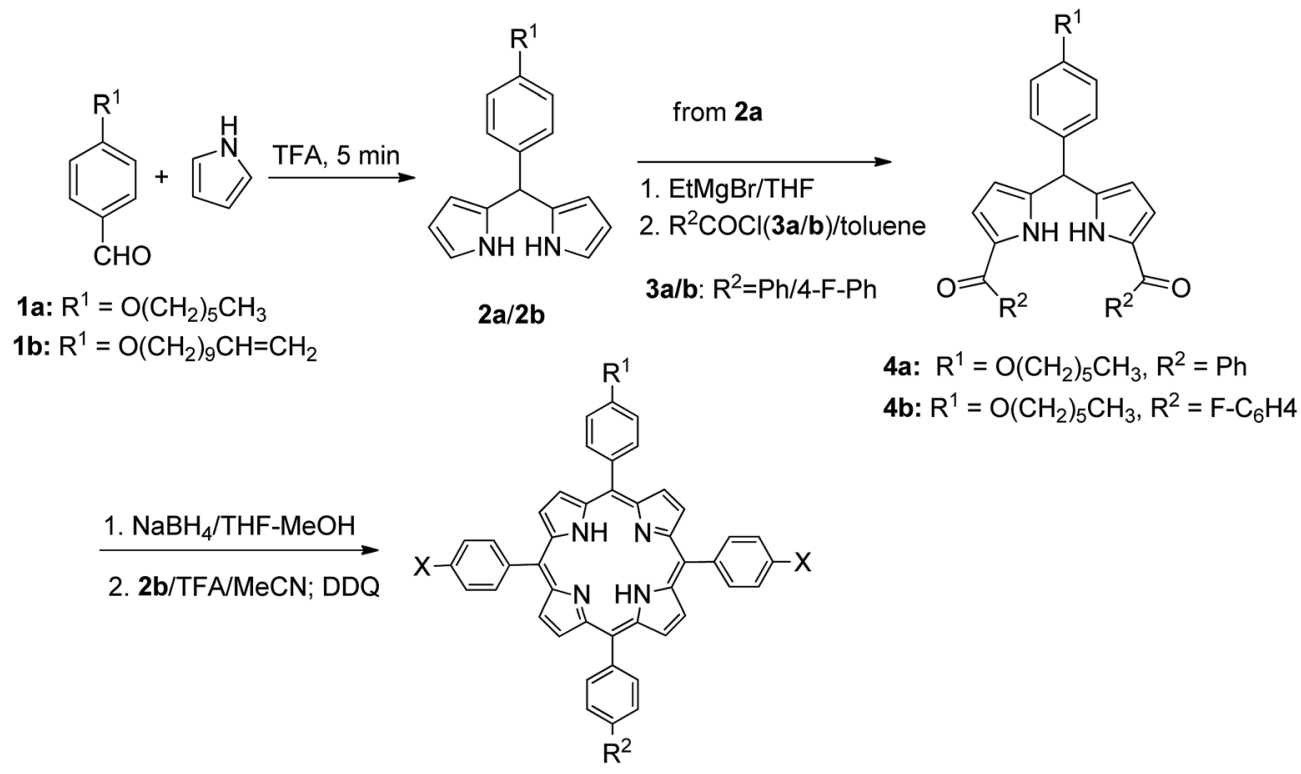

5a: $\mathrm{R}^{1}=\mathrm{O}\left(\mathrm{CH}_{2}\right)_{5} \mathrm{CH}_{3}, \mathrm{R}^{2}=\mathrm{O}\left(\mathrm{CH}_{2}\right)_{9} \mathrm{CH}=\mathrm{CH}_{2}, \mathrm{X}=\mathrm{H}$

5b: $\mathrm{R}^{1}=\mathrm{O}\left(\mathrm{CH}_{2}\right)_{5} \mathrm{CH}_{3}, \mathrm{R}^{2}=\mathrm{O}\left(\mathrm{CH}_{2}\right)_{9} \mathrm{CH}=\mathrm{CH}_{2}, \mathrm{X}=\mathrm{F}$

Scheme 1 Syntheses of the prophyrins.

the alkyl silanes have to be synthesized separately. ${ }^{23}$ Hence, we followed electro-grafting for an easy attachment of the porphyrins on $\mathrm{Si}$ (111) surface through the strong $\mathrm{Si}-\mathrm{C}$ bond (Si-C $\left.\sim 76 \mathrm{kcal} \mathrm{mol}^{-1}\right) .^{23 b}$ Organic molecules having a cleavable group such as vinyl $(\mathrm{C}=\mathrm{C})$, ethynyl $(\mathrm{C} \equiv \mathrm{C})$, halide $(\mathrm{Cl}, \mathrm{Br}, \mathrm{I})$, tetraalkylammonium, and diazonium silane reacts with $\mathrm{H}$-terminated $\mathrm{Si}$, and can be deposited using electrografting process. The advantage of the process is that the deposition process can be monitored in situ by measuring the redox peak of the electrografting reaction.

Presently electrografting of the molecules $\mathbf{5 a}$ and $\mathbf{5 b}$ on highly-doped, commercially available Si (111) surfaces was achieved by conventional cyclic voltammetry (CV). The CVs (Fig. 1), recorded during electrochemical deposition of the molecules $\mathbf{5 a}$ and $\mathbf{5 b}$ on $\mathrm{Si}$ showed an irreversible peak at $\sim 0.3 \mathrm{~V}$, which was earlier assigned for the bonding of an alkene with the $\mathrm{H}$-terminated Si surfaces. ${ }^{14 d}$ Moreover, no peak at $0.3 \mathrm{~V}$ appeared when the $\mathrm{CV}$ was run using the TBAP solution alone, but similar peak was observed with 1-undecene (taken as reference). This indicated covalent attachment of the porphyrin molecules at the H-terminated Si surfaces is through terminal double bond. The possible electrochemical reactions in the process is schematically shown in ESI (Fig. SL1†). In the first step, application of a negative potential to the working electrode produces a radical on silicon and a proton. The $\mathrm{Si}$ radical subsequently reacts with the alkene function of $\mathbf{5 a}$ and $\mathbf{5 b}$ to form the $\mathrm{Si}-\mathrm{C}$ bond, and generates a C-centred radical $\beta$ to the $\mathrm{Si}$ atom. A subsequent transfer $\mathrm{H}$ atom from another $\mathrm{Si}-\mathrm{H}$ bond generates a new $\mathrm{Si}$ radical to propagate the process. Formation of the $\mathrm{Si}-\mathrm{C}$ bond resulted in the irreversible oxidation peak at $\sim 0.3 \mathrm{~V}$. As the number of scans increased, the peak diminished owing to the non-availability of nucleophilic Si atoms at the surface. Using different number of scans $(5,10,20,25$ and 30), a compact monolayer, as revealed by AFM (Fig. 2) was prepared at 25 and 30 scans respectively with $\mathbf{5 a}$ and $\mathbf{5 b}$. At higher scans, formation of multilayers was evident by AFM analysis (data not shown).

\section{Monolayer characterization}

In order to ascertain the monolayer deposition on $\mathrm{Si}$, the electro-grafted materials were characterized by contact angle measurement, polarized FT-IR spectroscopy, X-ray reflectivity (XRR), ellipsometry, AFM, secondary ion mass spectrometry (SIMS) and electrochemistry. The contact angles of deionized water in case of Si wafers, grafted with $5 \mathbf{a}$ and $5 \mathbf{b}$ were $\sim 58^{\circ}$ and $64^{\circ}$ respectively, whereas for the cleaned Si wafer it was $84^{\circ}$. The observed contact angles were much less than the reported values $\left(97-108^{\circ}\right)$ of the methyl terminated alkyl chains. ${ }^{24}$ This suggested interaction of the water molecule with the porphyrins, possibly through their pyrrole rings, which is possible only when the molecules are tilted. This was also confirmed by ellipsometry, where the average thicknesses of respective monolayers were found to be $\sim 2.3 \pm 0.2 \mathrm{~nm}$ in case of $5 \mathrm{a}$ and $2.9 \pm 0.2 \mathrm{~nm}$ with $\mathbf{5 b}$. The XRR experiments, carried out at room temperature with the monolayers further confirmed their thicknesses. The reflectivity data (Fig. 3) was fitted in MOTOFIT software, using Parratt's formalism. The scattering length density (SLD) values of the monolayers were calculated from the density of monolayer and molecular formula of molecule according to eqn (1).

$$
\rho=\frac{N N_{\mathrm{a}} \rho_{\text {mass }}}{M_{\mathrm{R}}} \times \sum_{i=1}^{n} b_{\mathrm{c} i}
$$



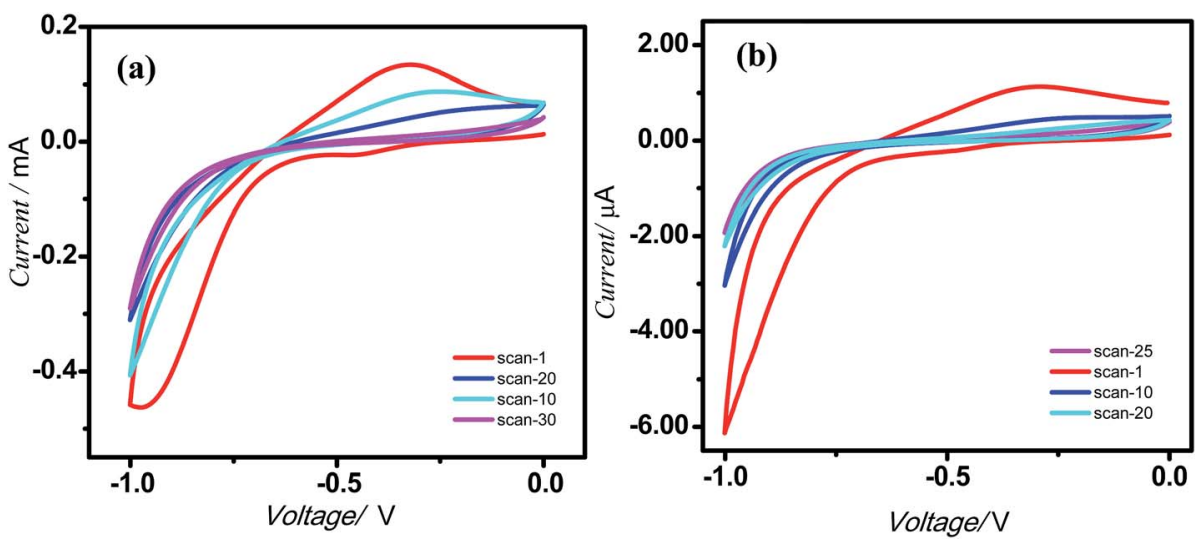

Fig. 1 CVs indicating electrografting of the molecules on silicon $\left(\mathrm{n}^{++}\right)$wafers. (a) $5 \mathrm{a}$; (b) $5 \mathrm{~b}$. The deposition was carried out under $\mathrm{N}_{2}$ atmosphere at a scan rate of $0.05 \mathrm{~V} \mathrm{~s}^{-1}$ using Si wafers as the $\mathrm{WE}, \mathrm{Pt}$ as the $\mathrm{CE}, \mathrm{Ag} / \mathrm{AgCl}$ as the $\mathrm{RE}, 0.1 \mathrm{M} \mathrm{Bu} \mathrm{NP}_{4}$ as the electrolyte and the porphyrins $(1 \mu \mathrm{M})$ in dry $\mathrm{CH}_{2} \mathrm{Cl}_{2}$.

$$
b_{i}=\frac{e^{2}}{4 \pi \varepsilon_{0} m c^{2}} f_{1 i}
$$

where $N_{\mathrm{a}}$ is Avogadro number, $\rho_{\text {mass }}$ is the mass density of the material, $M_{\mathrm{R}}$ is its relative molecular mass and $b_{\mathrm{c} i}$ is the bound coherent scattering length of the $i^{\text {th }}$ atom of a molecule with $n$ atoms. For X-rays, the scattering length for each atom was calculated using eqn (2), where $e$ is the charge on a single electron, $\varepsilon_{0}$ is the permittivity of free space, $m$ is the mass of an electron and $c$ is the speed of light. The scattering factor $\left(f_{1 \mathrm{i}}\right)$ for an atom of element $i$ is available in literature. ${ }^{25}$ The SLD profile was calculated using eqn (3), where $N$ is the total number of layers, $z$ is the distance from the top interface and erf is the error function.

$$
\rho=\sum_{i=0}^{N} \frac{\rho_{i}-\rho_{i+1}}{2}\left(1+\operatorname{erf}\left(\frac{z-z_{i}}{\sqrt{2} \sigma_{i}}\right)\right)
$$

From the plot of SLD $v s$. interface distance, the thicknesses for $5 \mathbf{a}$ and $\mathbf{5 b}$ were found to be $2.54 \pm 0.02 \mathrm{~nm}$ and $3.05 \pm 0.03$ $\mathrm{nm}$ respectively (Fig. 3 inset). These values are lower than the theoretically calculated (using Molkel software) length $\sim 3.9 \mathrm{~nm}$ of the porphyrins. The roughness values for the monolayers of 5a $24.0 \AA$ (SLD $\left.=0.22 \times 10^{-6} \AA^{-2}, \chi_{5 a}{ }^{2}=0.04913\right)$ and $5 \mathbf{b} 29.7 \AA$ $\left(\mathrm{SLD}=2.23 \times 10^{-6} \AA^{-2} \chi_{5 \mathrm{a}}{ }^{2}=0.03049\right)$ were close to their thicknesses estimated by ellipsometry. The XRR data also indicated that the tilt angles of the monolayers were $\sim 39^{\circ}$ and $51.4^{\circ}$ for $\mathbf{5 a}$ and $\mathbf{5 b}$ respectively.

The AFM analyses revealed that the monolayers were more organized with lesser number of voids and hillocks, and the void depths were $\sim 2.3 \mathrm{~nm}$ for $\mathbf{5 a}$ and $2.9 \mathrm{~nm}$ for $\mathbf{5 b}$ (Fig. 2). The RMS and average roughnesses values of the monolayers were 1.45 and $1.16 \mathrm{~nm}$ for $\mathbf{5 a}$, and 0.89 and $0.73 \mathrm{~nm}$ for $\mathbf{5 b}$. Compared to $\mathbf{5 a}$, the monolayers of $\mathbf{5 b}$ were more compact and uniform with larger grain size. The fast scan $\left(10 \mathrm{~V} \mathrm{~s}^{-1}\right) \mathrm{CVs}$ (Fig. 4$)$ of the monolayers exhibited a reversible peak at $+0.8 \mathrm{~V}$ for the respective porphyrin moieties and no such peak was observed in bare silicon and undecene deposited silicon. The net charge transferred during the oxidation process, calculated from the area under the oxidation peak were $4.5 \times 10^{-8} \mathrm{C}$ and $8.8 \times 10^{-7}$
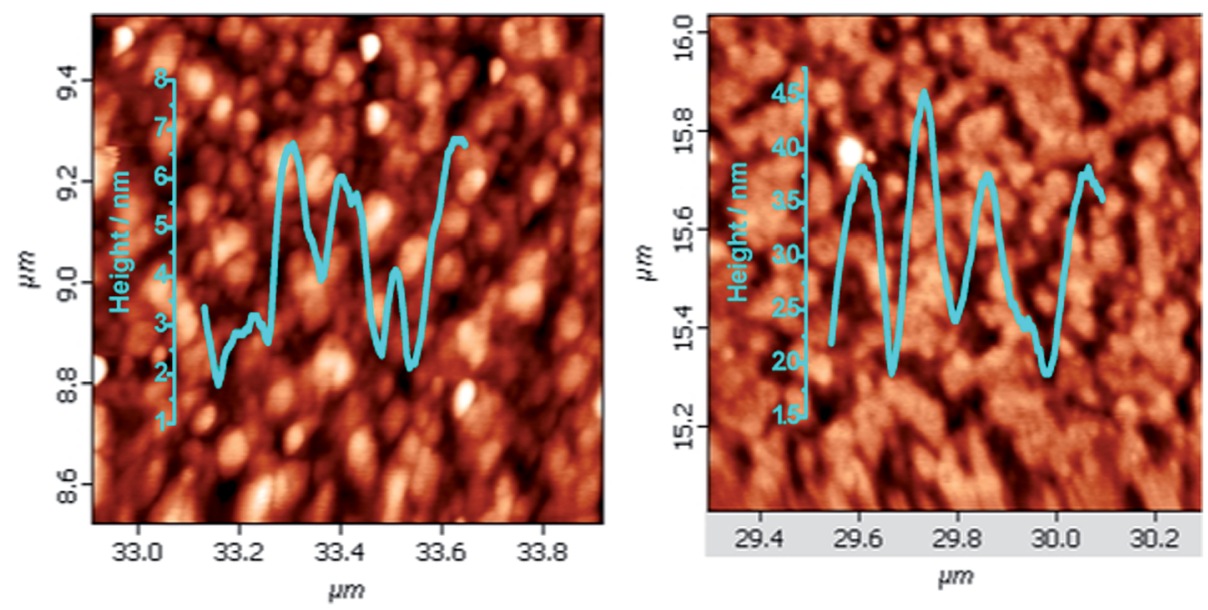

Fig. 2 AFM images $(1 \mu \mathrm{m} \times 1 \mu \mathrm{m})$ for the monolayers of (a) 5a; (b) 5b, electro-grafted on silicon $\left(\mathrm{n}^{++}\right)$wafers. 

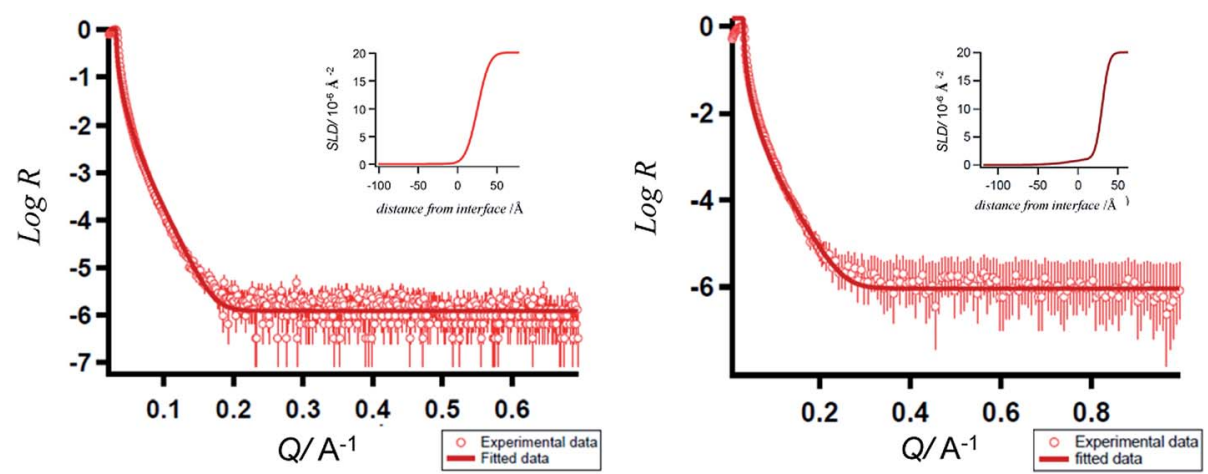

Fig. 3 XRR curves of the porphyrins-grafted monolayers on silicon $\left(\mathrm{n}^{++}\right)$wafers. (a) 5a; (b) $5 \mathrm{~b}$; insets: SLD plots.

C respectively for $\mathbf{5 a}$ and $\mathbf{5 b}$. These amounted to surface coverages of $4.3 \times 10^{11}$ and $3.4 \times 10^{12}$ molecules $\mathrm{cm}^{-2}$ respectively for $\mathbf{5 a}$ and $\mathbf{5 b}$. Thus, the surface covered by $\mathbf{5 b}$ was $\sim 8$ times that by 5a. These data are consistent with the AFM analyses, both revealing more compact monolayers with $\mathbf{5 b}$ than 5a. This may be because of hydrogen bonding amongst the $\mathrm{F}$ and $\mathrm{H}$ atoms of the porphyrin phenyl moieties.

Identifying the $\mathrm{C}-\mathrm{H} / \mathrm{F}-\mathrm{C}$ interaction as a hydrogen bond is questioned due to the poor acceptor ability of C-bonded $\mathrm{F}$ atoms compared to the $\mathrm{O}$ - and $\mathrm{N}$-atoms, if present. ${ }^{26}$ However, distinct hydrogen bond character has been reported in the layered crystal structure of fluoroaromatics, where $\mathrm{C}-\mathrm{H} / \mathrm{F}-\mathrm{C}$ interactions contribute significantly in stabilizing the layers. This has been attributed to activation of the ortho-aromatic protons by the $\mathrm{F}$ atom that may override the poor acceptor nature of the C-bonded halogen. ${ }^{27}$ In addition, the face-to-face noncovalent interaction in arene-perfluoroarene system is ubiquitous, and widely recognised as one of the major driving forces in forming robust supramolecular assemblies. ${ }^{28}$ This primarily involves stabilizing Coulombic interactions, and has been reported with several fluoroaromatic compounds. ${ }^{29}$ In the present case, the parallel offset disposition of the fluorophenyl moieties of adjacent porphyrin molecules may also be responsible for the compact monolayers of $\mathbf{5 b}$.
The SIMS of the monolayer of 5a showed peaks due to the porphyrin fragments at $m / z 665,646,461,400,356$ and 324 amu. In case of $\mathbf{5 b}$, the peaks appeared at a lower mass range viz. $\mathrm{m} / \mathrm{z}$ 457, 407, 387 and 334 amu. Nevertheless, the SIMS data (Fig. 5(a) and (b)) of the monolayers of $\mathbf{5 a}$ and $\mathbf{5 b}$ confirmed deposition of their respective monolayers on the Si wafers. In case of 5a monolayers, the secondary ions knocked down the porphyrin moiety from the alkyl spacer, attached to the $\mathrm{Si}$ surface. Subsequent ionization of the released porphyrin moiety provided the mass fragments at higher masses. Possibly, the secondary ions cannot penetrate the more compact $\mathbf{5 b}$ monolayers, resulting in the fragmentation of the porphyrin moiety in the middle to generate the low molecular weight mass peaks of the truncated porphyrin moiety.

The polarized FTIR spectra (Fig. 6) for the monolayers of 5a exhibited N-H stretching frequency at $3249 \mathrm{~cm}^{-1}$, symmetric $\left(\nu_{\mathrm{s}}\right)$ and asymmetric stretching modes $\left(\nu_{\mathrm{a}}\right)$ of $\mathrm{CH}_{2}$ group at 2842 and $2910 \mathrm{~cm}^{-1}$ and of $\mathrm{CH}_{3}$ group at 2877 and $2949 \mathrm{~cm}^{-1}$. In contrast, the respective IR absorption peaks of the monolayers of 5b were at $3255 \mathrm{~cm}^{-1}, 2855$ and $2925 \mathrm{~cm}^{-1}$, and at 2871 and $2961 \mathrm{~cm}^{-1}$. In pure solid alkane monolayers, the hydrocarbon chains exist in an all-trans configuration such that the carbon backbone of each molecule lies in single planes. However, in liquid form, there is a substantial twisting about
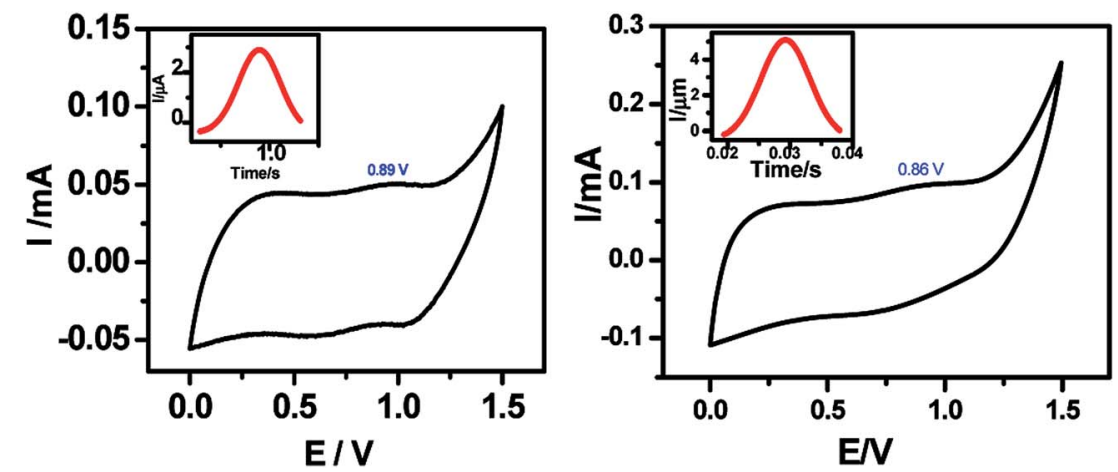

Fig. 4 Fast scan CVs for the monolayers of (a) $5 a$; (b) $5 b$; electro-grafted on silicon $\left(\mathrm{n}^{++}\right)$wafers. The $C V$ s were recorded under $\mathrm{N}_{2}$ atmosphere at a scan rate of $10 \mathrm{~V} \mathrm{~s}^{-1}$ using the respective monolayer-grafted $\mathrm{Si}$ as the $\mathrm{WE}, \mathrm{Pt}$ as the $\mathrm{CE}$ and $\mathrm{Ag} / \mathrm{AgCl}$ as the $\mathrm{RE}$, and $0.1 \mathrm{M} \mathrm{Bu} \mathrm{N}_{4} \mathrm{NP}$ as the electrolyte. The reversible peaks are indicated by circles. Insets show the magnified redox peaks, after background correction and converting the potential scale into time scale. 
(a)

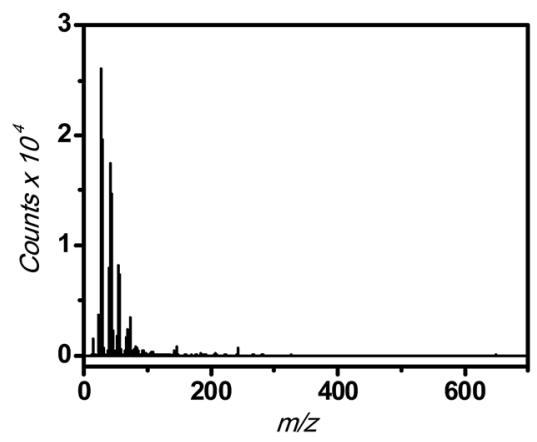

(c)

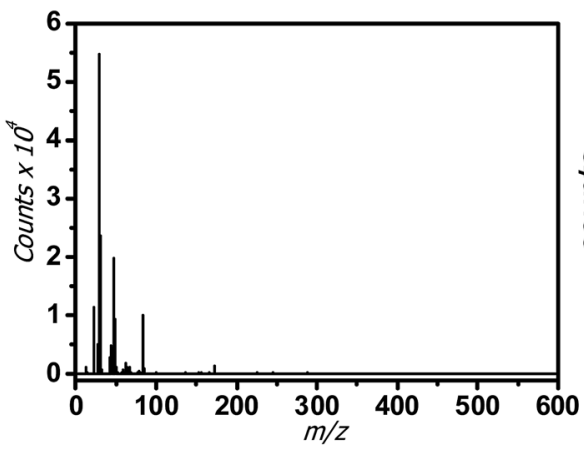

(b)

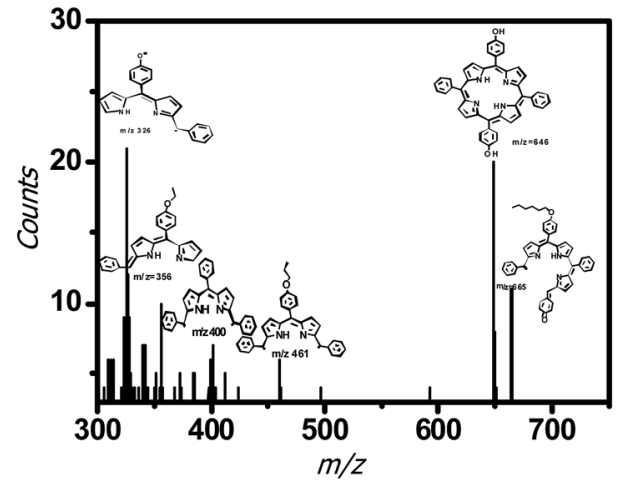

(d)

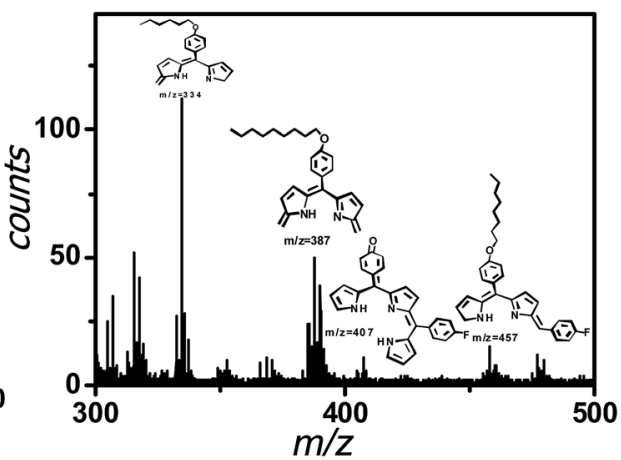

Fig. 5 SIMS of the porphyrins-grafted monolayers on silicon $\left(n^{++}\right)$wafers. (a) 5a; (b) enlarged plot for 5a; (c) 5b; (d) enlarged plot for $5 b$.

the individual bonds; these out-of-plane twists alter the frequency of the $\mathrm{CH}_{2}$ vibrational modes. ${ }^{30}$ Thus, the IR peaks due to the $\mathrm{CH}_{2}$ vibrational modes can provide better insights about the proposed van der Waals interactions between the porphyrin rings, parallely anchored on Si. Our IR data showed that the alkyl chains in the monolayers of $\mathbf{5 a}$ are more rigid like in pure solid alkanes, while that in the monolayers of $\mathbf{5 b}$ are more liquid like and twisted. Presumably, in case of $\mathbf{5 b}$, the phenyl rings of the porphyrin moiety are more tightly packed setting the alkyl chains free to twist. But in case of 5a, proper packing requires stacking of the porphyrins as well as the alkyl moieties at a tilt angle of $39^{\circ}$. This rigidifies the alkyl chains in 5 a.

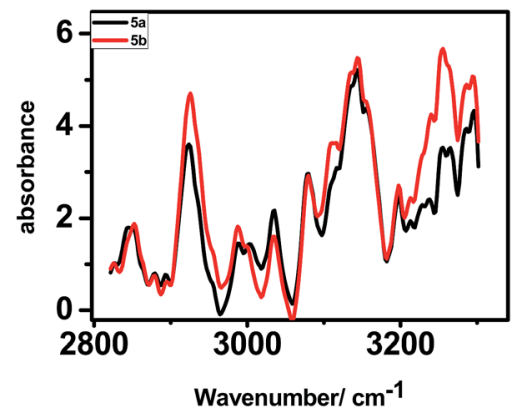

Fig. 6 Polarized FTIR spectra of the monolayers of $5 a$ and $5 b$ on silicon $\left(\mathrm{n}^{++}\right)$wafers.

\section{I-V characteristics}

Typical current voltage $(I-V)$ curves of $\mathrm{Hg} / \mathrm{molecule} / \mathrm{Si}$ (111) wafers are shown in Fig. 7. The hybrid assemblies, prepared from $5 \mathbf{a}$ and $\mathbf{5 b}$ showed reversible NDR behaviour at room temperature with current PVRs of 10 and 100, and peak positions (voltage) at $1.18 \mathrm{~V}$ and $1.09 \mathrm{~V}$ respectively. The details of the $I-V$ curves are shown in Table Sl $1 \dagger$ Interestingly majority of the devices, constructed with both the systems were stable during repetitive voltage scanning for $8 \mathrm{~h}$ in positive and negative bias voltages, without any reduction in current or the NDR effect. However, the reversible NDR effect showed only a marginal hysteresis. The Si-alkyl//Hg junctions, used in the studies are very stable, and exclude any possibility of penetration of $\mathrm{Hg}$ drops through pinholes or diffusion of mercury vapor through the SAM. Thus, the measured $I-V$ is expected to be direct. The statistical analyses of data, and junction yields are extremely valuable to discriminate artifacts from real data. ${ }^{31} \mathrm{In}$ the present work, we constructed 96 and 48 devices, respectively with the compounds $\mathbf{5 a}$ and $\mathbf{5 b}$. Of these, 80 and 43 devices, made of $\mathbf{5 a}$ and $\mathbf{5 b}$ showed stable (up to $8 \mathrm{~h}$ ), and reversible NDR property, although 94 and 46 of these devices showed reversible NDR behavior.

The complete PVR statistics of the devices are shown as the ESI (Table Sl $2 \uparrow$ and the accompanying pi-chart), and summarized here. With compound 5a, the PVR values of $36 \%$ of the devices were $8-10$, while an additional $37 \%$ of the devices 

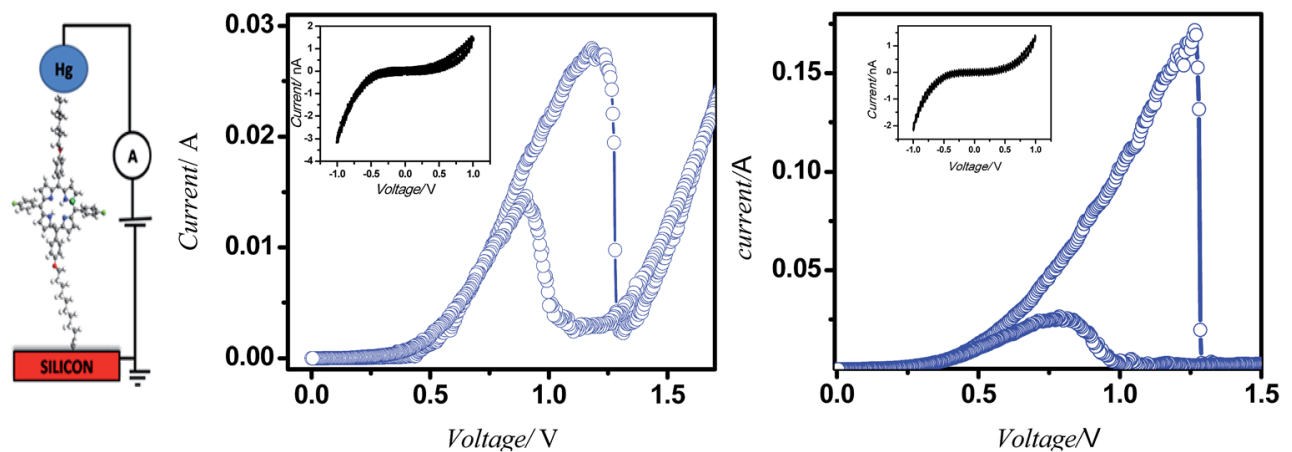

Fig. 7 Device design and characteristics. (a) $I-V$ measurement set up; (b) and (c) $I-V$ plots of the monolayers of $5 a$ and $5 b$ on silicon $\left(\mathrm{n}^{++}\right)$wafers respectively.
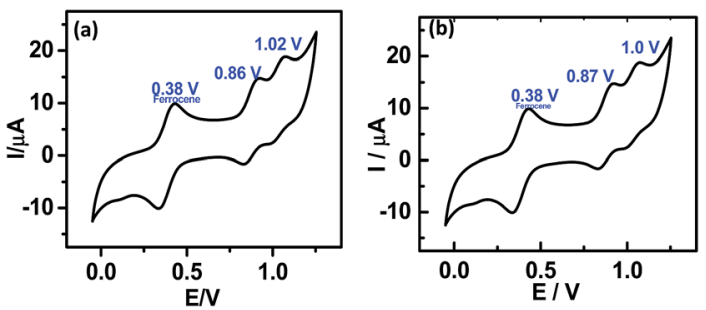

Fig. $8 \mathrm{CV}$ of the porphyrins in solution phase using ferrocene as the standard. (a) 5a; (b) $5 b$.

showed PVR values 5-8. The device statistics of the monolayers of $\mathbf{5 b}$ were more impressive with $39 \%$ of the devices showing PVR values of $80-100$, an additional $33 \%$ with PVR of 50-80, and an additional $24 \%$ with PVR of $10-50$. The $I-V$ characteristics of the solid state devices can be understood in terms of the molecular properties observed in the solution. Presently, the current flow in both the solid-state devices (Fig. 4) as well as in the respective porphyrin solutions (Fig. 8) showed same oxidation peaks.

The correspondence between the solution and solid-state results suggested that the fundamental molecular electronic properties of the porphyrins are retained in the solid-state devices. Hence, the forward bias current-flow should be determined by the HOMO states of the molecules, while their respective LUMO states would dictate the reverse bias current.
Thus, the NDR effect in forward bias is a result of alignment of the HOMO levels of the molecules with the Fermi-levels of the electrodes. Various mechanisms such as charge transferinduced change of the charge state, and chemical/ conformational changes under finite bias have been proposed to explain NDR phenomenon. ${ }^{32}$ It is possible that presently, the NDR behaviour depends on a match (resonant tunnelling) between the Fermi levels of electrodes and the HOMO levels of molecules sandwiched between the electrodes, followed by a mismatch of HOMO levels of the oxidized molecules with the Fermi-levels of electrodes. The hypothesis is consistent with the Aviram-Ratner model of molecular rectification. ${ }^{4 a}$ However, involvement of additional mechanisms can't be excluded.

\section{Theoretical interpretation}

For further clarification, the theoretical calculations of the electronic transport behaviour were carried out. The ground state geometries of the molecules $\mathbf{5 a}$ and $\mathbf{5 b}$ were optimized by $a b$ initio molecular orbital calculations. The ionic optimization of molecules $\mathbf{5 a}$ and $\mathbf{5 b}$ was carried out without any symmetry constraint at the B3LYP/6-31G (d,p) level of theory. The geometrical parameters of both molecules were found to be same, except for the $\mathrm{C}-\mathrm{H}$ and $\mathrm{C}-\mathrm{F}$ bond lengths, which were $1.09 \AA$ and $1.39 \AA$ A, respectively.

Our experimental results revealed that on applying voltage, initially there was a slow rise in the current due to tunnelling.

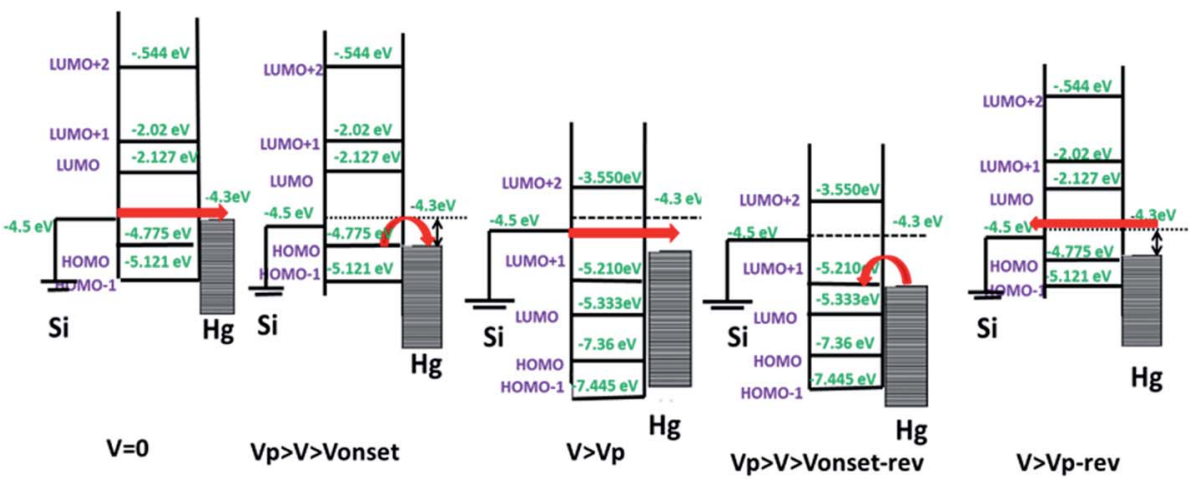

Fig. 9 Diagramatic presentation of the NDR mechanism for a $\sigma-\pi-\sigma$ system. 
But at $V_{\text {onset }}$ the HOMO level of the molecule would align in resonance with the Fermi level of $\mathrm{Hg}$. This can explain the sharp increase in current at $V_{\text {onset }}$. At $V_{\mathrm{p}}$, the molecules get oxidized to the +1 state, causing the misalignment with the Fermi-levels of $\mathrm{Hg}$, and resulting in the current drops. When the voltage is reduced in the reverse scan, the new device will be $\mathrm{Si}$ / porphyrin ${ }^{+1} / \mathrm{Hg}$. At $V_{\text {onset-rev, }}$ the Fermi level of $\mathrm{Hg}$ would align with the LUMO of porphyrin ${ }^{+1}$. This induces a sharp increase in the current due to resonance tunnelling through the molecule. It again drops at $V_{\mathrm{p} \text {-rev }}$ as the molecule gets misaligned with the Fermi levels of $\mathrm{Hg}$ during its reduction. The observed small hysteresis may be due to conformational changes in the molecule after oxidation. The experimentally observed voltages are in qualitative agreement with the theoretically calculated HOMOLUMO values of $\mathbf{5 a}$ and $\mathbf{5 b}$ and their respective +1 oxidation states, using $a b$ initio (GAMESS software) (data shown in ESI, Table SL3 $\dagger$ ). The mechanism of NDR effect in $\mathbf{5 a}$ and $\mathbf{5 b}$ is explained schematically in Fig. 9.

\section{Conclusions}

In summary, we have synthesized two di-O-alkylated porphyrin molecules as prototype $\sigma-\pi-\sigma$ systems, and electro-grafted them on H-terminated Si to form monolayers. The $I-V$ characteristics of the monolayers revealed pronounced reversible NDR effects with peak-to-valley current ratio of $\sim 10$ and 100 . The NDR effects were relatively stable during repetitive voltage scanning for $8 \mathrm{~h}$ in the positive and negative bias, without any reduction in current or in the NDR effect. The higher PVR, observed with the device containing the fluorophenylporphyrin moiety 5b suggested its better pre-organization possibly by hydrogen bonding through the $\mathrm{F}$ atoms, compared to the device, fabricated using the non-fluorinated porphyrin, 5a. Theoretical simulations of $\mathrm{Si} /$ porphyrin/Hg structure showed that the NDR effect is intrinsic to the porphyrin molecules. The NDR effect was explained using the $a b$ initio molecular-orbital theoretical calculations.

\section{Experimental section}

\section{General methods in synthesis}

Reagents and solvents (Sigma-Aldrich and Fluka) were of synthetic grade. Pyrrole and benzoyl chloride used after distillation. 4-Hydroxybenzaldehyde was used after crystallization. All solvents were dried and distilled before use. Tetrahydrofuran (THF) was distilled from Na under argon. Acetone was dried over $\mathrm{Na}_{2} \mathrm{CO}_{3}$ and HPLC grade acetonitrile was used. The ${ }^{1} \mathrm{H}$ NMR and ${ }^{13} \mathrm{C}$ NMR spectra were recorded with $200 / 300 / 500$ (50/75/100) $\mathrm{MHz}$ spectrometers using deuterated solvents as the internal standards. The mass spectrometry was carried out with a MSMS (410 Prostar Binary LC with 500 MS IT PDA Detectors, Varian Inc, USA) and MALDI-TOF/TOF (BrukerUltraflex II) data systems.

4-Hexyloxybenzaldehyde (1a) and 4-(10-undecenyloxy)benzaldehyde (1b). A mixture of 4-hydroxybenzaldehyde $(4.0 \mathrm{~g}$, $32.7 \mathrm{mmol})$, 1-bromohexane $(6.50 \mathrm{~g}, 39.3 \mathrm{mmol})$ or 1-bromo-10undecene $(9.16 \mathrm{~g}, 39.3 \mathrm{mmol}), \mathrm{K}_{2} \mathrm{CO}_{3}(5.52 \mathrm{~g}, 40 \mathrm{mmol})$ and
$\mathrm{Bu}_{4} \mathrm{NI}(10 \mathrm{~mol} \%)$ in acetone $(100 \mathrm{~mL})$ was refluxed till the reaction was complete $(c f$. TLC, $\sim 16 \mathrm{~h})$. The mixture was filtered, and concentrated in vacuum. The residue was taken in $\mathrm{Et}_{2} \mathrm{O}$ $(40 \mathrm{~mL})$ and washed with $\mathrm{H}_{2} \mathrm{O}(2 \times 10 \mathrm{~mL})$ and brine $(1 \times 20$ $\mathrm{mL}$ ), dried, and concentrated in vacuo. The residue was purified by column chromatography (silica gel, 5\% EtOAc/hexane) to give pure $1 \mathrm{a}(6.1 \mathrm{~g}, 91.2 \%)$ and $\mathbf{1 b}(8.1 \mathrm{~g}, 91 \%)$.

Compound 1a. colorless liquid; IR (film, $\nu / \mathrm{cm}^{-1}$ ): $3019(\mathrm{~s})$, 2928 (s), 2856 (s), 1687 (s); ${ }^{1} \mathrm{H}$ NMR (200 MHz, $\left.\mathrm{CDCl}_{3}\right): \delta 0.90(\mathrm{t}$, $J=6.4 \mathrm{~Hz}, 3 \mathrm{H}), 1.15-1.49(\mathrm{~m}, 6 \mathrm{H}), 1.71-1.88(\mathrm{~m}, 2 \mathrm{H}), 4.01(\mathrm{t}, J=$ $6.0 \mathrm{~Hz}, 2 \mathrm{H}), 6.97$ (d, $J=9.5 \mathrm{~Hz}, 2 \mathrm{H}), 7.80$ (d, $J=9.5 \mathrm{~Hz}, 2 \mathrm{H}), 9.85$ (s, 1H) ppm; ${ }^{13} \mathrm{C}$ NMR (50 MHz, $\left.\mathrm{CDCl}_{3}\right): \delta$ 13.6, 22.2, 25.3, 28.7, 31.2, 68.1, 114.4, 129.6, 131.5, 163.9, 190.04 ppm; MSMS (m/z): $207(100)[\mathrm{M}+\mathrm{H}]^{+}$; anal. calcd for $\mathrm{C}_{13} \mathrm{H}_{18} \mathrm{O}_{2}: \mathrm{C}, 75.69 ; \mathrm{H}, 8.80$. Found: C, 75.34; H, 9.06\%.

Compound 1b. Colorless liquid; IR (film, $\nu / \mathrm{cm}^{-1}$ ): $3019(\mathrm{~s})$, 2928, 2856 (s), 1687 (s); ${ }^{1} \mathrm{H}$ NMR (200 MHz, $\mathrm{CDCl}_{3}$ ): $\delta$ 1.21-1.57 (m, 12H), 1.72-1.95 (m, 2H), 1.96-2.15 (m, 2H), $4.05(\mathrm{t}, J=6.0$ $\mathrm{Hz}, 2 \mathrm{H}), 4.85-5.08$ (m, 2H), 5.67-5.99 (m, 1H), 6.99 (d, $J=8.0$ $\mathrm{Hz}, 2 \mathrm{H}), 7.83$ (d, $J=8.0 \mathrm{~Hz}, 2 \mathrm{H}), 9.88$ (s, 1H) ppm; ${ }^{13} \mathrm{C}$ NMR (50 $\left.\mathrm{MHz}, \mathrm{CDCl}_{3}\right): \delta 25.9,28.9,29.0,29.3,29.4,33.7,68.4,114.1$, 114.8, 129.9, 131.9, 139.1, 164.3, 190.6 ppm; MSMS (m/z): 275.1 (100) $[\mathrm{M}+\mathrm{H}]^{+}$; anal. calcd for $\mathrm{C}_{18} \mathrm{H}_{26} \mathrm{O}_{2}$ : C, 78.79; H, 9.55. Found: C, 79.02; H, 9.55\%.

Dipyrromethanes $2 \mathrm{a}$ and $2 \mathbf{b}$. A mixture of pyrrole (250 $\mathrm{mmol})$, compound $\mathbf{1 a}$ or $\mathbf{1 b}(10 \mathrm{mmol})$ and TFA $(1 \mathrm{mmol})$ was stirred under Ar for 5-10 min. After completion of the reaction, it was quenched with $0.1 \mathrm{M}$ aqueous $\mathrm{NaOH}(40 \mathrm{~mL})$ and extracted with EtOAc $(100 \mathrm{~mL})$. The organic layer was washed with $\mathrm{H}_{2} \mathrm{O}(3 \times 10 \mathrm{~mL})$ and brine $(1 \times 5 \mathrm{~mL})$, dried, and concentrated in vacuum. Excess pyrrole was removed by vacuum distillation at room temperature, and the residue column chromatographed (neutral alumina, 20\% EtOAc/ hexane) to give the respective products $2 \mathrm{a}(1.4 \mathrm{~g}, 42 \%)$ and $2 \mathbf{b}$ $(2.0 \mathrm{~g}, 52 \%)$, which were crystallized from hexane.

Compound 2a. White crystals; mp: $58{ }^{\circ} \mathrm{C}$; IR $\left(\nu / \mathrm{cm}^{-1}\right): 3463$ (m), 3019 (s), 2956 (s), 2859 (s), 2399 (w); ${ }^{1} \mathrm{H}$ NMR $(200 \mathrm{MHz}$, $\left.\mathrm{CDCl}_{3}\right): \delta 0.92(\mathrm{t}, J=6.2 \mathrm{~Hz}, 3 \mathrm{H}), 1.25-1.50(\mathrm{~m}, 6 \mathrm{H}), 1.68-1.85$ $(\mathrm{m}, 2 \mathrm{H}), 3.93(\mathrm{t}, J=6.4 \mathrm{~Hz}, 2 \mathrm{H}), 5.42(\mathrm{~s}, 1 \mathrm{H}), 5.85-5.93(\mathrm{~m}, 2 \mathrm{H})$, 6.12-6.22 (m, 2H), 6.61-6.68 (m, 2H), $6.84(\mathrm{~d}, J=7.8 \mathrm{~Hz}, 2 \mathrm{H})$, $7.12(\mathrm{~d}, J=7.8 \mathrm{~Hz}, 2 \mathrm{H}), 7.89$ (broad s, $2 \mathrm{H}$ ) ppm; ${ }^{13} \mathrm{C} \mathrm{NMR}$ $\left(50 \mathrm{MHz}, \mathrm{CDCl}_{3}\right): \delta 14.1,22.7,25.9,29.4,31.7,43.4,68.3,107.2$, 108.6, 114.8, 117.2, 129.5, 133.1, 134.2, 158.4 ppm; MSMS (CI, $m / z): 321.2(100)[\mathrm{M}-\mathrm{H}]^{+}$; anal. calcd for $\mathrm{C}_{21} \mathrm{H}_{26} \mathrm{~N}_{2} \mathrm{O}: \mathrm{C}, 78.22$; H, 8.13; N, 8.69. Found: C, 78.60; H, 8.17; N 8.54\%.

Compound $2 \boldsymbol{b}$. White crystals; mp: $64{ }^{\circ} \mathrm{C}$; IR $\left(\nu / \mathrm{cm}^{-1}\right): 3463$ (m), 3019 (s), 2928 (s), 2856 (s), 2399 (w), 1639 (w); ${ }^{1} \mathrm{H}$ NMR $\left(200 \mathrm{MHz}, \mathrm{CDCl}_{3}\right): \delta$ 1.21-1.59 $(\mathrm{m}, 12 \mathrm{H}), 1.69-1.84(\mathrm{~m}, 2 \mathrm{H})$, 1.95-2.17 (m, 2H), $3.94(\mathrm{t}, J=6.0 \mathrm{~Hz}, 2 \mathrm{H}), 4.85-5.09(\mathrm{~m}, 2 \mathrm{H})$, $5.43(\mathrm{~s}, 1 \mathrm{H}), 5.65-5.98(\mathrm{~m}, 3 \mathrm{H}), 6.10-6.21(\mathrm{~m}, 2 \mathrm{H}), 6.65-6.74(\mathrm{~m}$, $2 \mathrm{H}), 6.85$ (d, $J=8.5 \mathrm{~Hz}, 2 \mathrm{H}), 7.12$ (d, $J=8.5 \mathrm{~Hz}, 2 \mathrm{H}), 7.95$ (broad s, 2H) ppm; ${ }^{13} \mathrm{C} \mathrm{NMR} \mathrm{(50} \mathrm{MHz,} \mathrm{CDCl}_{3}$ ): $\delta$ 26.2, 29.1, 29.3, 29.5, 29.7, 33.9, 43.4, 68.3, 107.2, 108.6, 114.3, 114.9, 117.2, 129.5, 133.1, 134.2, 139.4, 158.4 ppm; MSMS (CI, $m / z): 391.1(100)[\mathrm{M}+$ $\mathrm{H}]^{+}$; anal. calcd for $\mathrm{C}_{26} \mathrm{H}_{34} \mathrm{~N}_{2} \mathrm{O}: \mathrm{C}, 79.96 ; \mathrm{H}, 8.77 ; \mathrm{N}, 7.17$. Found: C, 79.62, H, 8.77, N, 7.26\%. 
Diacyldipyrromethanes $4 \mathbf{a}$ and $4 \mathbf{b}$. A solution of EtMgBr in THF ( $8.1 \mathrm{mmol})$ was slowly injected to a stirred solution of $2 \mathrm{a}$ $(0.524 \mathrm{~g}, 1.62 \mathrm{mmol})$ in toluene $(25 \mathrm{~mL})$ under argon. After stirring for $0.5 \mathrm{~h}$ at room temperature, the acid chloride $\mathbf{3 a}$ or $\mathbf{3 b}$ (4.05 $\mathrm{mmol})$ in toluene $(2 \mathrm{~mL})$ was injected into the resulting brown solution over $10 \mathrm{~min}$, and stirring continued for an additional $10 \mathrm{~min}$. The reaction was quenched with aqueous saturated $\mathrm{NH}_{4} \mathrm{Cl}(10 \mathrm{~mL})$ and the mixture extracted with EtOAc $(20 \mathrm{~mL})$. The organic extract was washed with $\mathrm{H}_{2} \mathrm{O}(2 \times 10 \mathrm{~mL})$ and brine $(1 \times 5 \mathrm{~mL})$, dried, and concentrated in vacuum. The residue was column chromatographed (neutral alumina, 25\% EtOAc/hexane) to obtain brown oil as a $4: 1$ mixture of diacetyl and monoacetyl derivatives of $\mathbf{2 a}$. The required compounds $\mathbf{4 a}$ $(0.532 \mathrm{~g}, 62 \%)$ and $\mathbf{4 b}(0.422 \mathrm{~g}, 46 \%)$ were obtained in pure form by triturating the oils with $\mathrm{MeOH}$.

Compound 4a. Light brown powder; mp: $150{ }^{\circ} \mathrm{C}$; IR $\left(\nu / \mathrm{cm}^{-1}\right)$ : 3225 (m), 3017 (s), 2928 (s), 2856 (s), 1610 (s); ${ }^{1} \mathrm{H}$ NMR (200 $\left.\mathrm{MHz}, \mathrm{CDCl}_{3}\right): \delta 0.89(\mathrm{t}, J=6.5 \mathrm{~Hz}, 3 \mathrm{H}), 1.21-1.45(\mathrm{~m}, 6 \mathrm{H}), 1.71-$ $1.88(\mathrm{~m}, 2 \mathrm{H}), 3.94(\mathrm{t}, J=6.5 \mathrm{~Hz}, 2 \mathrm{H}), 5.60(\mathrm{~s}, 1 \mathrm{H}), 5.91-6.05(\mathrm{~m}$, $2 \mathrm{H}), 6.52-6.66(\mathrm{~m}, 2 \mathrm{H}), 6.88(\mathrm{~d}, J=6.8 \mathrm{~Hz}, 2 \mathrm{H}), 7.25-7.65(\mathrm{~m}$, $8 \mathrm{H}), 7.77$ (d, $J=6.8 \mathrm{~Hz}, 4 \mathrm{H}), 11.08$ (s, 2H) ppm; ${ }^{13} \mathrm{C}$ NMR (50 $\left.\mathrm{MHz}, \mathrm{CDCl}_{3}\right): \delta 14.0,22.6,26.1,29.2,29.3,31.8,44.1,68.1,111.0$, $114.9,120.7,128.0,129.4,129.7,131.0,131.6$, 138.4, 141.1, 158.6, 184.4 ppm; MS (DI, $m / z): 530$ (100) $[\mathrm{M}]^{+}$; anal. calcd for $\mathrm{C}_{35} \mathrm{H}_{34} \mathrm{~N}_{2} \mathrm{O}_{3}$ : C, 79.22; H, 6.46; N, 5.28. Found: C, 79.04, H, 6.52, $\mathrm{N}, 5.52 \%$.

Compound $4 \boldsymbol{b}$. Light brown powder; mp: $120^{\circ} \mathrm{C}$; IR $\left(\nu / \mathrm{cm}^{-1}\right)$ : 3275 (m), 3018 (s), 2932 (s), 2871 (s), 1610 (s); ${ }^{1} \mathrm{H}$ NMR (300 MHz, acetone- $\left.D_{6}\right): \delta 0.87-0.93(\mathrm{~m}, 3 \mathrm{H}), 1.21-1.38(\mathrm{~m}, 6 \mathrm{H}), 1.68-$ $1.82(\mathrm{~m}, 2 \mathrm{H}), 3.99(\mathrm{t}, J=6.2 \mathrm{~Hz}, 2 \mathrm{H}), 5.83(\mathrm{~s}, 1 \mathrm{H}), 5.95-6.18(\mathrm{~m}$, 2H), 6.75-6.97 (m, 4H), 7.16-7.48 (m, 6H), 7.88-8.05 (m, 4H), 11.12 (broad s, 2H) ppm; ${ }^{13} \mathrm{C}$ NMR (75 $\mathrm{MHz} \mathrm{CDCl}_{3}$ ): $\delta 13.9,22.5$, 25.7, 29.2, 31.6, 43.5, 43.9, 68.1, 111.0, 114.8, 115.0, 115.4, 120.5, 129.3, 129.5, 130.7, 131.3, 131.5, 131.7, 141.0, 158.3, 162.5, 182.9 ppm; MSMS (CIMS, $\mathrm{m} / \mathrm{z}$ ): $567.4(100)[\mathrm{M}+1]^{+}$; anal. calcd for $\mathrm{C}_{35} \mathrm{H}_{32} \mathrm{~F}_{2} \mathrm{~N}_{2} \mathrm{O}_{3}$ : C, 74.19; $\mathrm{H}, 5.69 ; \mathrm{N}, 4.94$. Found: C, 73.79, H, $5.43, \mathrm{~N}, 4.89 \%$. The ${ }^{13} \mathrm{C}-{ }^{19} \mathrm{~F}$ couplings were not analysed.

Porphyrins $5 \mathbf{a}$ and $\mathbf{5 b}$. To a stirred solution of the respective diacetyldipyrromethanes $\mathbf{4 a}$ or $\mathbf{4 b}(0.78 \mathrm{mmol})$ in dry $\mathrm{THF} /$ $\mathrm{MeOH}(10: 1,34.3 \mathrm{~mL})$ was added $\mathrm{NaBH}_{4}(1.0 \mathrm{mmol})$ in portions. After the reduction was complete, the mixture was poured into aqueous saturated $\mathrm{NH}_{4} \mathrm{Cl}(60 \mathrm{~mL})$ and extracted with $\mathrm{CH}_{2} \mathrm{Cl}_{2}(100 \mathrm{~mL})$. The organic layer was washed with $\mathrm{H}_{2} \mathrm{O}$ $(2 \times 5 \mathrm{~mL})$ and brine $(1 \times 5 \mathrm{~mL})$, dried, and concentrated in vacuum to get the respective dicarbinols as foam like solids.

Mixtures of each of these compounds and dipyrromethane 2b $(0.78 \mathrm{mmol})$ in $\mathrm{CH}_{3} \mathrm{~N}(350 \mathrm{~mL})$ were stirred to get a homogeneous solution. TFA ( $9.49 \mathrm{mmol})$ was slowly added into these under rapid stirring, followed by addition of DDQ $(2.34 \mathrm{mmol})$ after $5 \mathrm{~min}$. The reaction was stirred for $1 \mathrm{~h}$ at room temperature and then quenched with $\mathrm{Et}_{3} \mathrm{~N}(9.49 \mathrm{mmol})$. The mixture was passed through a pad of alumina and eluted with $\mathrm{CH}_{2} \mathrm{Cl}_{2}$ until the eluent was colourless. The resulting solution was concentrated, passed through a pad of silica gel, and eluted with $\mathrm{CH}_{2} \mathrm{Cl}_{2}$ to remove the non-porphyrinic products. The purple fractions were combined and concentrated in vacuo to give the porphyrins $5 \mathbf{a}(0.069 \mathrm{~g}, 10 \%)$ and $5 \mathbf{b}(0.143 \mathrm{~g}, 20 \%)$ as purple solids, which were recrystallized from $\mathrm{CHCl}_{3} / \mathrm{MeOH}$.

Compound 5a. Purple crystals; mp: $230{ }^{\circ} \mathrm{C}$; IR $\left(\nu / \mathrm{cm}^{-1}\right): 3433$ (s), 3019 (s), 2928 (s), 2399 (w), 1643 (w); ${ }^{1} \mathrm{H}$ NMR (200 MHz, $\left.\mathrm{CDCl}_{3}\right): \delta-2.79(\mathrm{~s}, 2 \mathrm{H}), 0.97(\mathrm{t}, J=6.6 \mathrm{~Hz}, 3 \mathrm{H}), 1.12-1.75(\mathrm{~m}$, $18 \mathrm{H}), 1.88-2.20(\mathrm{~m}, 6 \mathrm{H}), 4.23(\mathrm{t}, J=6.4 \mathrm{~Hz}, 4 \mathrm{H}), 4.82-5.08(\mathrm{~m}$, $2 \mathrm{H})$, 5.75-5.98 (m, 1H), 7.21-7.38 (m, 4H), 7.61-7.79 (m, 6H), 8.02-8.28 (m, 8H), 8.78-8.96 (m, 8H) ppm; ${ }^{13} \mathrm{C}$ NMR (50 MHz, $\left.\mathrm{CDCl}_{3}\right): \delta 14.1,22.7,25.9,26.2,29.0,29.2,29.5,29.6,31.7,33.9$, 68.4, 112.8, 113.6, 113.8, 114.2, 118.7, 120.2, 130.8, 134.2, 135.6, 135.8, 138.2, 139.3, 159.1, 161.2164.5 ppm; MALDI-TOF $(\mathrm{m} / \mathrm{z})$ : $882[\mathrm{M}]^{+}$; anal. calcd for $\mathrm{C}_{61} \mathrm{H}_{62} \mathrm{~N}_{4} \mathrm{O}_{2}: \mathrm{C}, 82.96 ; \mathrm{H}, 7.08 ; \mathrm{N}, 6.34$. Found: C, 82.94; H, 7.03; N, 6.04\%.

Compound 5b. Purple crystals; mp: $225^{\circ} \mathrm{C}$; IR $\left(\nu / \mathrm{cm}^{-1}\right): 3434$ (s), 3019 (s), 2927 (s), 2850 (s), 1643 (w); ${ }^{1} \mathrm{H}$ NMR (200 MHz, $\left.\mathrm{CDCl}_{3}\right): \delta-2.81(\mathrm{~s}, 2 \mathrm{H}), 1.07(\mathrm{t}, J=6.6 \mathrm{~Hz}, 3 \mathrm{H}), 1.25-1.59(\mathrm{~m}$, $18 \mathrm{H}), 1.85-2.17(\mathrm{~m}, 6 \mathrm{H}), 4.23(\mathrm{t}, J=6.0 \mathrm{~Hz}, 4 \mathrm{H}), 4.86-5.12(\mathrm{~m}$, $2 \mathrm{H}), 5.72-5.97(\mathrm{~m}, 1 \mathrm{H}), 7.15-7.32(\mathrm{~m}, 4 \mathrm{H}), 7.35-7.5(\mathrm{~m}, 4 \mathrm{H})$, 8.03-8.25 (m, 8H), 8.75-8.99 (m, 8H) ppm; ${ }^{13} \mathrm{C}$ NMR (50 MHz, $\left.\mathrm{CDCl}_{3}\right): \delta 14.2,22.7,25.9,26.3,29.5,29.7,31.7,32.0,68.3$, $112.8,113.6,113.8,118.7,120.2$, 130.9, 134.2, 135.6, 135.8, 138.2, 159.1, 161.2, 164.5 ppm; MALDI-TOF $(\mathrm{m} / \mathrm{z}): 918[\mathrm{M}]^{+}$. anal. calcd for $\mathrm{C}_{61} \mathrm{H}_{60} \mathrm{~N}_{4} \mathrm{O}_{2} \mathrm{~F}_{2}$ : C, 79.71; H, 6.58; N, 6.10. Found: C, 79.84; H, 6.64; N, 6.03\%. The ${ }^{13} \mathrm{C}-{ }^{19} \mathrm{~F}$ couplings were not analysed.

\section{Preparation of $\mathrm{H}$-terminated $\mathrm{Si}$ wafers}

$\mathrm{N}$-type silicon wafers (orientation: 111; resistivity: 0.001-0.005 $\Omega \mathrm{cm}$ ) and $40 \% \mathrm{NH}_{4} \mathrm{~F}$ were purchased from Siltronix and Fluka, respectively. The Si (111) wafers, cut into small pieces $(\sim 0.5 \mathrm{~cm} \times 1.5 \mathrm{~cm})$ were cleaned by heating them in $3: 1(\mathrm{v} / \mathrm{v})$ of conc. $\mathrm{H}_{2} \mathrm{SO}_{4}: 30 \% \mathrm{H}_{2} \mathrm{O}_{2}$ (piranha) for $10 \mathrm{~min}$ at $80{ }^{\circ} \mathrm{C}$. The wafers were removed, washed with excess $\mathrm{H}_{2} \mathrm{O}$ and, immersed successively in a deaerated (purged with Ar for $30 \mathrm{~min}$ ) $40 \%$ aqueous $\mathrm{NH}_{4} \mathrm{~F}$ for $10 \mathrm{~min}$, and $2 \%$ aqueous $\mathrm{HF}$ for $2 \mathrm{~min}$. The wafers were washed with deionized $\mathrm{H}_{2} \mathrm{O}$ for $1 \mathrm{~min}$, dried under a stream of $\mathrm{N}_{2}$ and immediately taken into the electrochemical cell to perform the electrografting of the porphyrins $\mathbf{5 a}$ and $\mathbf{5 b}$.

\section{Monolayer formation}

The electrochemical deposition of $\mathbf{5 a}$ and $\mathbf{5 b}$ was carried out by CV with a potentiostat/galvanostat system (model: AutolabPGSTAT 30) using the above Si wafers as the working electrode (WE), Pt as the counter electrode (CE) and $\mathrm{Ag} / \mathrm{AgCl}$ as the reference electrode (RE). The solution contained $0.1 \mathrm{M} \mathrm{Bu}_{4} \mathrm{NP}$ as the electrolyte and $\mathbf{5 a}$ and $\mathbf{5 b}(1 \mu \mathrm{M})$ in dry $\mathrm{CH}_{2} \mathrm{Cl}_{2}$. The $\mathrm{CV}$ was run from 0 to $-1 \mathrm{~V}$ for $25-50$ cycles at $0.05 \mathrm{~V} \mathrm{~s}^{-1}$ scan rate under an inert atmosphere. It was found that homogeneous monolayer was formed at 25 scans for $\mathbf{5 a}$ and 30 scans for $\mathbf{5 b}$. Homogeneity of monolayer was determined by AFM. After the CV scans, the WE was sonicated in $\mathrm{CH}_{2} \mathrm{Cl}_{2}$ for $10 \mathrm{~min}$ to remove the electrolyte and the unreacted or physisorbed $\mathbf{5 a}$ or $\mathbf{5 b}$. The WE was further washed with acetone, isopropanol and methanol to obtain the respective grafted monolayers. 


\section{Characterization of monolayer}

The monolayers were characterized in terms of thickness, using an ellipsometer (Sentech: model SE400adv), surface morphology by AFM (Multiview 4000, Nanonics) imaging, by de-ionized water contact angle (Data Physics System, model: OCA20), FT-IR (Bruker, 3000 Hyperion Microscope with Vertex 80 FTIR System, LN-MCT 315-025 detector) in polarized ATR $(20 \times$ objective) mode for 500 scans at an angle of $45^{\circ}$, XRR experiments (TTRAX3 theta-theta goniometer), performed using Cu$\mathrm{k} \alpha$ as the X-ray source in a fixed monochromator mode, and molecular mass by SIMS (BARC make, Kore's Technology software). The XRR data were fitted using MOTOFIT software. ${ }^{33}$ The roughness and thickness values of the grafted layers were determined at the minimum value of $\chi^{2}$ for the respective monolayers. The Levenberg-Marquardt algorithm (eqn (4)) was used for obtaining the minimum value of $\chi^{2}$, which defines a surface in a multidimensional error space. The deepest valley in the $\chi^{2}$ surface signifies minimum coefficient values of the fitting function. The CV of the grafted monolayer (as WE) was recorded from 0 to $1 \mathrm{~V}$ for 10 cycles at a scan rate $10 \mathrm{~V} \mathrm{~s}^{-1}$.

$$
\chi^{2}=\sum_{n=1}^{L} \frac{1}{L-P}\left(\frac{y_{n, \mathrm{obs}}-y_{n, \mathrm{calc}}}{y_{n, \mathrm{error}}}\right)^{2}
$$

\section{Junction and measurement setup}

To measure the $J-V$ characteristics, a metal/molecule/Si $\left(\mathrm{n}^{++}\right)$ structure was completed by using a tiny drop of liquid mercury of diameter $400 \mu \mathrm{m}$ as the counter electrode. The contact area in the grafted monolayer was $0.2 \mathrm{~mm}^{2}$. The $J-V$ curves were recorded at room temperature in a dark box using a pAmeter-dc voltage source (HP 4140).

\section{Acknowledgements}

One of the authors (KG) thanks Bhabha Atomic Research Centre for the financial support. The technical help by Mr A. Nelson for the MOTOFIT software is appreciated.

\section{References}

1 (a) B. Branchi, F. Simeone and M. Rampi, Top. Curr. Chem., 2012, 313, 85-119; (b) C. C. Jia and X. F. Guo, Chem. Soc. Rev., 2013, 42, 5642-5660; (c) M. Ratner, Nat. Nanotechnol., 2013, 8, 378-381; (d) D. Xiang, H. Jeong, T. Lee and D. Mayer, Adv. Mater., 2013, 25, 4845-4867; (e) R. Lovrinčić, O. Kraynis, R. Har-Lavan, A.-E. Haj-Yahya, W. Li, A. Vilan and D. Cahen, J. Phys. Chem. Lett., 2013, 4, 426-430; (f) H. J. Yoon, C. M. Bowers, M. Baghbanzadeh and G. M. Whitesides, J. Am. Chem. Soc., 2014, 136, 16-19.

2 (a) M. A. Reed, C. Zhou, C. J. Muller, T. P. Burgin and J. M. Tour, Science, 1997, 278, 252-254; (b) J. Chen, M. A. Reed, A. M. Rawlett and J. M. Tour, Science, 1999, 286, 1550-1552; (c) E. P. A. M. Bakkers, A. W. Marsman, L. W. Jenneskens and D. Vanmaekelbergh, Angew. Chem.,
Int. Ed., 2000, 39, 2297-2299; (d) R. E. Holmlin, R. F. Ismagilow, R. Haag, V. Mujica, M. A. Ratner, M. A. Rampi and G. M. Whitesides, Angew. Chem., Int. Ed., 2001, 40, 2316-2320; (e) D. J. Wold, R. Haag, M. A. Rampi and C. D. Frisbie, J. Phys. Chem. B, 2002, 106, 2813-2816; (f) A. Salomon, D. Cahen, S. Lindsay, J. Tomfohr, V. B. Engelkes and C. D. Frisbie, Adv. Mater., 2003, 15, 1881-1890; $(g)$ R. Holmlin, E. R. Haag, M. L. Chabinyc, R. F. Ismagilow, A. E. Cohen, A. Terfort, M. A. Rampi and G. M. Whitesides, J. Am. Chem. Soc., 2001, 123, 5075-5085.

3 R. M. Metzger, Acc. Chem. Res., 1999, 32, 950-957.

4 (a) A. Aviram and M. A. Ratner, Chem. Phys. Lett., 1974, 29, 277-283; (b) C. A. Mirkin and M. A. Ratner, Annu. Rev. Phys. Chem., 1992, 43, 719-754; (c) M. H. Dvoret, D. Esteve and C. Urbina, Nature, 1996, 379, 413-413.

5 A. Joachim, J. K. Gimzewski and A. Aviram, Nature, 2000, 408, 541-548.

6 J. Chen, W. Wang, M. A. Reed, A. M. Rawlett, D. W. Price and J. M. Tour, Appl. Phys. Lett., 2000, 77, 1224-1226.

7 (a) Z. Liu, A. A. Yasseri, J. S. Lindsey and D. F. Bocian, Science, 2003, 302, 1543-1545; (b) C. Seabaugh, Y. C. Kuo and H. T. Yuan, IEEE Electron Device Lett., 1992, 13, 479-481; (c) D. H. Chow, H. L. Dunlap, W. Williamson III, S. Enquist, B. K. Gilbert, S. Subramaniam, P.-M. Lei and G. H. Bernstein, IEEE Electron Device Lett., 1996, 17, 69-71; (d) Z. J. Donhauser, B. A. Mantooth, K. F. Kelly, L. A. Bumm, J. D. Monnell, J. J. Stapleton, D. W. Price, A. M. Rawlett, D. L. Allara, J. M. Tour and P. S. Weiss, Science, 2001, 292, 2303-2307; (e) H. Inokawa, A. Fujiwara and Y. Takahashi, Appl. Phys. Lett., 2001, 79, 3618-3620; (f) I.-W. Lyo and P. Avouris, Science, 1989, 245, 1369-1371.

8 (a) P. Bedrossian, D. M. Chen, K. Mortensen and J. A. Golovchenko, Nature, 1989, 342, 258-260; (b) D. D. D. Ma, Y. G. Wang, L. Lu, C. S. Lee and S. T. Lee, Appl. Phys. Lett., 2002, 80, 1231-1233; (c) F.-R. F. Fan, J. Yang, L. Cai, D. W. Price, S. M. Dirk, D. Kosynkin, Y. Yao, A. M. Rawlett, J. M. Tour and A. J. Bard, J. Am. Chem. Soc., 2002, 124, 5550-5560; (d) M. Duati, C. Grave, N. Tcbeborateva, J. Wu, K. Müllen, A. Shaporenko, M. Zharnikov, J. K. Kriebel, G. M. Whitesides and M. A. Rampi, Adv. Mater., 2006, 18, 329-333; (e) J. L. Pitters and R. A. Wolkow, Nano Lett., 2006, 6, 390-397; (f) E. D. Mentovich, I. Kalifa, A. Tsukernik, A. Caster, N. Rosenberg-Shraga, H. Marom, M. Gozin and S. Richter, Small, 2008, 4, 55-58; (g) N. P. Guisinger, M. E. Greene, R. Basu, A. S. Baluch and M. C. Hersam, Nano Lett., 2004, 4, 55-59; (h) F. J. Ribeiro, W. Lu and J. Bernholc, ACS Nano, 2008, 2, 1517-1522.

9 T. Shinada, S. Okamoto, T. Kobayashi and I. Ohdomari, Nature, 2005, 437, 1128-1131.

10 S. Roy and A. Asenov, Science, 2005, 309, 388-390.

11 M. Jurow, A. E. Schuckman, J. D. Batteas and C. M. Drain, Coord. Chem. Rev., 2010, 254, 2297-2310.

12 (a) L. Esaki, Phys. Rev., 1958, 109, 603-604; (b) L. H. Dubois and R. G. Nuzzo, Annu. Rev. Phys. Chem., 1992, 43, 437463; (c) K. M. Roth, N. Dontha, R. B. Dabke, D. T. Gryko, C. Clausen, J. S. Lindsey, D. F. Bocian and W. G. Kuhrb, J. 
Vac. Sci. Technol., B: Microelectron. Nanometer Struct.Process., Meas., Phenom., 2000, 18, 2359-2364; (d) D. Gryko, J. Li, J. R. Diers, K. M. Roth, D. F. Bocian, W. G. Kuhr and J. S. Lindsey, J. Mater. Chem., 2001, 11, 1162-1180; (e) K. M. Roth, J. S. Lindsey, D. F. Bocian and W. G. Kuhr, Langmuir, 2002, 18, 4030-4040; (f) K. M. Roth, A. A. Yasseri, Z. Liu, R. B. Dabke, V. Malinovskii, K. H. Schweikart, L. Yu, H. Tiznado, F. Zaera, J. S. Lindsey, W. G. Kuhr and D. F. Bocian, J. Am. Chem. Soc., 2003, 125, 505-517; $(g)$ X. Lu, M. Li, C. Yang, L. Zhang, Y. Li, L. Jiang, H. Li, L. Jiang, C. Liu and W. Hu, Langmuir, 2006, 22, 3035-3039.

13 M.-Q. Long, K.-Q. Chen, L. Wang, W. Qing, B. S. Zou and Z. Shuai, Appl. Phys. Lett., 2008, 92, 243303.

14 (a) W. Han, E. N. Durantini, A. L. Moore, D. Gust, P. Rez, G. Leatherman, G. R. Sealey, N. J. Tao and S. M. Lindsay, J. Phys. Chem. B, 1997, 101, 10719-10725; (b) L. W. Yu, K. J. Chen, J. Song, J. M. Wang, J. Xu, W. Li and X. F. Huang, Thin Solid Films, 2007, 515, 5466-5470; (c) N. J. Tao, Phys. Rev. Lett., 1996, 76, 4066-4069; (d) S. P. Koiry, D. K. Aswal, A. K. Chauhan, V. Saxena, S. K. Nayak, S. K. Gupta and J. V. Yakhmi, Chem. Phys. Lett., 2008, 453, 68-72; (e) S. P. Koiry, D. K. Aswal, B. Jousselme, C. Majumdar, S. K. Gupta, S. Palacin and J. V. Yakhmi, Phys. E, 2010, 70, 135-140.

15 (a) K. Garg, A. Singh, A. K. Debnath, S. K. Nayak, S. Chattopadhyay, D. K. Aswal, Y. Hayakawa, S. K. Gupta and J. V. Yakhmi, Chem. Phys. Lett., 2010, 488, 27-31; (b) K. Garg, A. Singh, C. Majumder, S. K. Nayak, D. K. Aswal, S. K. Gupta and S. Chattopadhyay, Org. Electron., 2013, 14, 1189-1196.

16 (a) M. D. Newton, Chem. Rev., 1991, 91, 767-792; (b) A. Salomon, R. A. Yellin, A. Shanzer, A. Karton and D. Cahen, J. Am. Chem. Soc., 2004, 126, 11648-11657.

17 (a) W. B. Davis, W. A. Svec, M. A. Ratner and M. R. Waseliewski, Nature, 1998, 396, 60-63; (b) D. K. James and J. M. Tour, Top. Curr. Chem., 2005, 257, 33-62.

18 S. M. Sze, Semiconductor Devices: Physics and Technology, John Wiley and Sons, New York, 2002.

19 S. P. Koiry, D. K. Aswal, B. Jousselme, C. Majumdar, S. K. Gupta, S. Palacin and J. V. Yakhmi, Chem. Phys. Lett., 2010, 493, 135-140.

20 (a) A. D. Adler, F. R. Longo, J. D. Finarelli, J. Goldmacher, J. Assour and L. Korsakoff, J. Org. Chem., 1967, 32, 476-
476; (b) P. D. Rao, B. J. Littler, G. R. Geier III and J. S. Lindsey, J. Org. Chem., 2000, 65, 1084-1092.

21 J. M. Buriak, Chem. Rev., 2002, 102, 1271-1308.

22 (a) G. S. Tulevski, M. B. Myers, M. S. Hybertsen, M. L. Steigerwald and C. Nuckolls, Science, 2005, 309, 591594; (b) C. Toher and S. Sanvito, Phys. Rev. Lett., 2007, 99, 056801.

23 (a) S. Lenfant, C. Krzeminski, C. Delerue, G. Allan and D. Vuillaume, Nano Lett., 2003, 3, 741-746; (b) D. K. Aswal, S. P. Koiry, B. Jousselme, S. K. Gupta, S. Palacin and J. V. Yakhmi, Phys. E, 2009, 41, 325-344.

24 (a) D. K. Aswal, S. Lenfant, D. Guerini, J. V. Yakhmi and D. Vuillaume, Anal. Chim. Acta, 2006, 568, 84-108; (b) G. J. Kluth, M. M. Sung and R. Maboudian, Langmuir, 1997, 13, 3775-3780.

25 http://physics.nist.gov/PhysRefData/FFast/Text1995/ contents1995.html.

26 J. D. Dunitz and R. Taylor, Chem.-Eur. J., 1997, 3, 89-98.

27 T. S. Thakur, M. T. Kirchner, D. Blaser, R. Boese and G. R. Desiraju, CrystEngComm, 2010, 12, 2079-2085.

28 (a) J. H. Williams, Acc. Chem. Res., 1993, 26, 593-598; (b) T. Dahl, Acta Chem. Scand., 1994, 48, 95-106; (c) E. A. Meyer, R. K. Castellano and F. Diederich, Angew. Chem., Int. Ed., 2003, 42, 1210-1250.

29 (a) S. Bacchi, M. Benaglia, F. Cozzi, F. Demartin, G. Filippini and A. Gavezzotti, Chem.-Eur. J., 2006, 12, 3538-3546; (b) F. Cozzi, S. Bacchi, G. Filippini, T. Pilati and A. Gavezzotti, Chem.-Eur. J., 2007, 13, 7177-7184; (c) R. Annunziata, M. Benaglia, F. Cozzi, A. Mazzanti, B. Sieval, A. L. Demirel, J. W. M. Nissink, M. R. Linford, J. H. van der Maas, W. H. de Jeu, H. Zuilhof and E. J. R. Sudhölter, Langmuir, 1998, 14, 1759-1768.

30 (a) B. Sieval, A. L. Demirel, J. W. M. Nissink, M. R. Linford, J. H. van der Maas, W. H. de Jeu, H. Zuilhof and E. J. R. Sudhölter, Langmuir, 1998, 14, 1759-1768; (b) J. Taylor, H. Guo and J. Wang, Phys. Rev. B: Condens. Matter Mater. Phys., 2001, 63, 245407-245420.

31 (a) T.-W. Kim, G. Wang, H. Lee and T. Lee, Nanotechnology, 2007, 18, 315204; (b) C. A. Nijhuis, W. F. Reus, J. R. Barber, M. D. Dickey and G. M. Whitesides, Nano Lett., 2010, 10, 3611-3619; (c) C. A. Nijhuis, W. F. Reus and G. M. Whitesides, J. Am. Chem. Soc., 2009, 131, 17814-17827. 32 X. Zheng, W. Lu, T. A. Abtew, V. Meunier and J. Bernholc, ACS Nano, 2010, 4, 7205-7210.

33 A. Nelson, J. Appl. Crystallogr., 2006, 39, 273-276. 